\title{
Efficacy and safety of methotrexate in the treatment of rheumatoid arthritis: a retrospective study
}

\author{
Lijuan Wang^, Yingying Zhang, Lijie Zhu, Yasong Li \\ Department of Rheumatology and Immunology, Zhejiang Provincial People's Hospital, Affiliated People's Hospital, Hangzhou Medical College, \\ Hangzhou, China \\ Contributions: (I) Conception and design: L Wang; (II) Administrative support: Y Li; (III) Provision of study materials or patients: Y Li, L Wang, Y \\ Zhang; (IV) Collection and assembly of data: L Zhu; (V) Data analysis and interpretation: L Wang; (VI) Manuscript writing: All authors; (VII) Final \\ approval of manuscript: All authors. \\ Correspondence to: Yasong Li. Department of Rheumatology and Immunology, Zhejiang Provincial People's Hospital, Affiliated People's Hospital, \\ Hangzhou Medical College, 158 Shangtang Road, Hangzhou 310014, China. Email: lysong2@163.com.
}

Background: The clinical efficacy and safety of leflunomide (LFN) at a dose of $10 \mathrm{mg}$ /day in the treatment of patients with rheumatoid arthritis (RA) is still unclear. We conducted this retrospective study to identify its efficacy and safety in comparison with methotrexate (MTX) at a dose of $10 \mathrm{mg} /$ week.

Methods: We enrolled RA patients who were treated in our hospital from January 2013 to December 2020, and the American College of Rheumatology (ACR) 1987 criteria were adopted. The following data was collected: age, duration of disease, erythrocyte sedimentation rate (ESR), C-reactive protein (CRP), rheumatoid factor (RF), cyclic citrullinated peptide (CCP) antibody, white blood cell (WBC), and hemoglobin $(\mathrm{Hb})$ level. The primary outcomes included the changes of the above variables and the incidence of adverse events after treatment in both groups.

Results: From January 2013 to December 2020, a total of 612 patients with RA treated in our hospital were screened. After excluding cases that did not meet the inclusion criteria, 33 cases remained in LFN group, and there were 59 cases in the MTX group. The baseline characteristics were similar between the LFN and MTX groups. After 24 weeks of treatment, there were still no significant differences between the two groups in all of the above variables. The infection rate was slightly higher in patients treated with MTX than those treated with LFN, while diarrhea episodes were more common in the LFN group.

Conclusions: Our data indicated that compared with MTX at a dose of $10 \mathrm{mg} /$ week, a low dose of LFN at $10 \mathrm{mg} /$ day might be a preferable treatment choice for RA patients.

Keywords: Rheumatoid arthritis (RA); leflunomide (LFN); methotrexate (MTX); retrospective

Submitted Aug 06, 2021. Accepted for publication Nov 17, 2021.

doi: 10.21037/apm-21-2331

View this article at: https://dx.doi.org/10.21037/apm-21-2331

\section{Introduction}

Leflunomide (LFN) is an isoxazole immunosuppressant with antiproliferative activity, and its mechanism is mainly to inhibit the activity of dihydrowhey dehydrogenase, thus affecting the pyrimidine synthesis of activated lymphocytes.
It is usually used to treat rheumatoid arthritis (RA). There is evidence that LFN is both beneficial and safe for treating patients with RA, and it is considered to be equivalent to treatment with methotrexate (MTX) or sulfasalazine (SFA) (1-3).

\footnotetext{
^ ORCID: 0000-0002-0864-8229.
} 
The compliance (maintaining the prescribed dose) and adherence (maintaining the therapy for a long time) to disease-modifying antirheumatic drug (DMARD) treatment are the two most common problems in treating RA patients. Due to multiple factors such as multi drug system, adverse drug events, and high treatment cost, it is difficult to obtain long-term clinical results in routine clinical practice, especially for patients who lack social security coverage.

In order to seek treatment alternatives conducive to treatment compliance and adherence, and maintain the effectiveness of anti-rheumatic therapy, we conducted the present retrospective study, in which the efficacy and safety results of RA patients treated with $10 \mathrm{mg}$ /day LFN was compared with that of those treated with $10 \mathrm{mg} /$ week MTX. Patients with active RA were followed up with LFN at a dose of $10 \mathrm{mg}$ per day for 6 months. According to the standards of the American College of Rheumatology (ACR), these patients achieved clinical improvement, and there was no evidence of serious adverse events (4). We present the following article in accordance with the STROBE reporting checklist (available at https://dx.doi.org/10.21037/apm-212331).

\section{Methods}

\section{Patients selection}

This retrospective study was based on RA patients who were treated in our hospital from January 2013 to December 2020. The ACR1987 (5) criteria were adopted for diagnosing RA. Active RA was defined as the presence of joint swelling (SJ) and pain (PJ) for at least 6 weeks, morning stiffness lasting more than 30 minutes, and erythrocyte sedimentation rate (ESR) of at least $20 \mathrm{~mm} / \mathrm{h}$. Previous treatment with DMARD should have been suspended for at least 1 month before enrollment, and treatment with LFN or MTX should have been suspended for at least 3 months. We also included newly diagnosed patients who had not yet received DMARD treatment. The minimum duration of treatment was 24 weeks.

Prednisone or its equivalent was allowed to be used for the shortest possible time, and the daily routine dose did not exceed $10 \mathrm{mg}$. Patients were excluded if they were not adult, had other immune diseases, had a history of high alcohol consumption, or were pregnant/likely to be pregnant. The baseline laboratory studies required for inclusion were: normal leukocyte count, hemoglobin concentration greater than $12 \mathrm{~g} / \mathrm{dL}$, and a negative pregnancy test in case of women.

\section{Data collection}

The following data was collected: age, duration of disease, ESR, C-reactive protein (CRP), rheumatoid factor (RF), cyclic citrullinated peptide (CCP) antibody, white blood cell (WBC), and hemoglobin ( $\mathrm{Hb})$. The primary outcomes included the changes of the above variables and the incidence of adverse events after treatment in both groups.

\section{Statistical analysis}

The efficacy between groups was compared by independent sample analysis of variance. If $\mathrm{P} \leq 0.05$, the data was considered statistically significant. Safety was analyzed according to the percentage of adverse events reported by each group.

\section{Ethical statement}

The study was conducted in accordance with the Declaration of Helsinki (as revised in 2013). The study was approved by institutional ethics board of Zhejiang Provincial People's Hospital (No. 2021QT359). Informed consent was not required since this was a retrospective study, and data were obtained from the database of our hospital.

\section{Results}

As shown in Figure 1, from January 2013 to December 2020, a total of 212 patients with RA treated in our hospital were screened. Of the 212 cases, 80 were given LFN at a dose of $10 \mathrm{mg} /$ day, while the other 132 were given MTX at a dose of $10 \mathrm{mg} /$ week. After excluding cases that did not meet the inclusion criteria, there were 33 cases remaining in LFN group ( 37 had other immune diseases, 2 were younger than 18 years, and 8 were lost to follow-up), and 59 cases remaining in MTX group (61 had other immune disease, 1 was younger than 18 years, and 11 were lost to follow-up).

The baseline characteristics of the participants are shown in Table 1. There were no significant differences between the two groups in the main indicators, such as age, duration of disease, ESR, CRP, RF, CCP, WBC, and Hb. As shown in Table 2, after 24 weeks of treatment, there were still no significant differences between the two groups in all of the following variables: age, duration of disease, ESR, CRP, RF, CCP, WBC, and $\mathrm{Hb}$.

The occurrence of adverse events is shown in Table 3. Adverse events occurred in 10 cases $(30.3 \%)$ in the LFN group, and 15 cases (25.4\%) in the MTX group. Infections, 


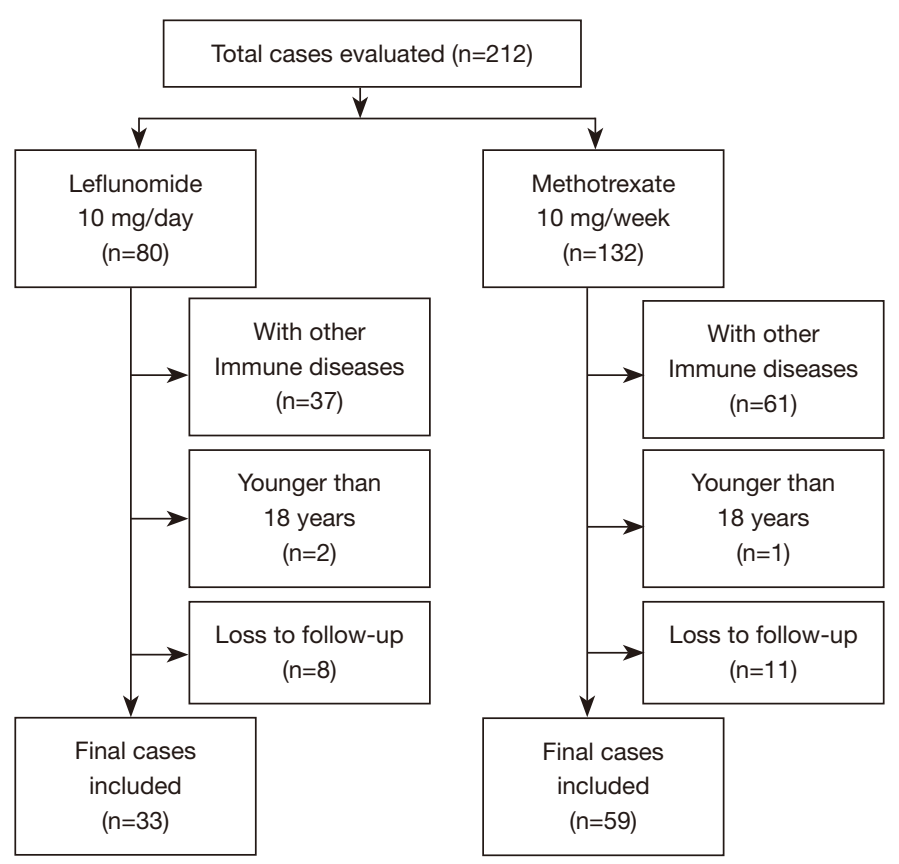

Figure 1 The enrollment of rheumatoid arthritis patients in this study.

Table 1 The baseline characteristics of participants

\begin{tabular}{|c|c|c|c|}
\hline Variable & Leflunomide group $(n=33)( \pm S D)$ & Methotrexate group $(n=59)( \pm S D)$ & $P$ value \\
\hline Duration of the disease, years & $6.0( \pm 0.52)$ & $6.2( \pm 0.49)$ & 0.66 \\
\hline $\mathrm{ESR}, \mathrm{mm} / \mathrm{h}$ & $87.1( \pm 27.8)$ & $64.4( \pm 38.7)$ & 0.13 \\
\hline CRP, mg/L & $34.2( \pm 14.2)$ & $36.9( \pm 16.7)$ & 0.74 \\
\hline CCP antibody & $1,299.7( \pm 117.6)$ & $914.4( \pm 121.5)$ & 0.95 \\
\hline WBC, $\times 10^{9} / \mathrm{L}$ & $7.3( \pm 2.8)$ & $6.1( \pm 2.4)$ & 0.24 \\
\hline $\mathrm{Hb}, \mathrm{g} / \mathrm{L}$ & $151.9( \pm 11.2)$ & $121.6( \pm 15.6)$ & 0.53 \\
\hline
\end{tabular}

ESR, erythrocyte sedimentation rate; CRP, C-reactive protein; RF, rheumatoid factor; CCP, cyclic citrullinated peptide; WBC, white blood cell; $\mathrm{Hb}$, hemoglobin.

which included upper respiratory tract infections (patients had corresponding upper respiratory symptoms or imaging characteristics) and urinary infections (urinary sediment microscopic examination of leukocytes greater than 5 per high-power visual field) were observed in both groups, and the infection rate was slightly higher among patients treated with MTX. Gastrointestinal adverse events were also present in both groups, and diarrhea episodes (stool frequency increased or stool shape changed) were more common in the LNF group. No serious adverse events were recorded, and there were no adverse events that were lifethreatening or required the termination of treatment in both groups.

\section{Discussion}

In daily practice, rheumatologists need an effective and safe treatment plan for patients with RA, and to be flexible in administration, so as to maintain the adherence and compliance to the treatment, and achieve the purpose of 
Table 2 Comparisons of the two groups after 24 weeks of treatment

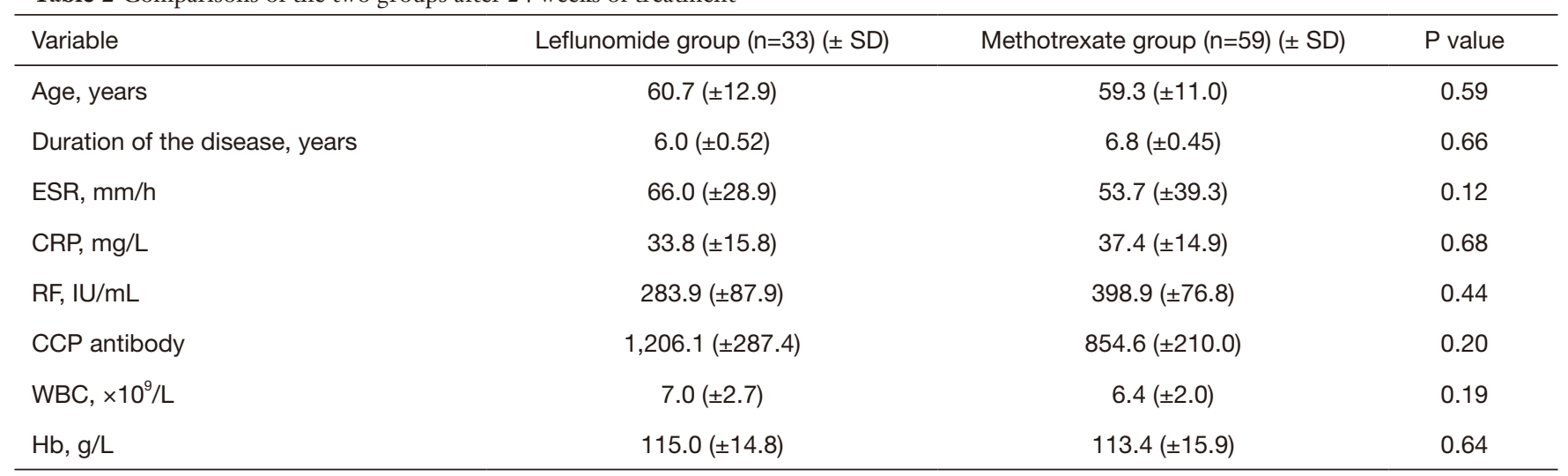

ESR, erythrocyte sedimentation rate; CRP, C-reactive protein; RF, rheumatoid factor; CCP, cyclic citrullinated peptide; WBC, white blood cell; Hb, hemoglobin.

Table 3 Adverse events among the two groups

\begin{tabular}{lcc}
\hline Adverse events & Leflunomide $(\mathrm{n}=33)$, No. $(\%)$ & Methotrexate $(\mathrm{n}=59)$, No. $(\%)$ \\
\hline Upper respiratory tract infections & $4(12.1)$ & $17(28.8)$ \\
Urinary infections & $2(6.1)$ & $4(6.8)$ \\
Gastroenteritis & $1(3.0)$ & $2(3.4)$ \\
Herpes zoster & $0(0)$ & $1(1.7)$ \\
Vulvovaginitis & $1(3.0)$ & $4(6.8)$ \\
Gastritis & $9(27.3)$ & $15(25.4)$ \\
Diarrhea & $7(21.2)$ & $1(1.7)$ \\
Abdominal distension & $2(6.1)$ & $8(13.6)$ \\
Nausea & $2(6.1)$ & $8(13.6)$ \\
\hline
\end{tabular}

clinical improvement and remission of the disease (6).

The drug LFN is an abiotic DMARD of isoxazole. After administration, it can inhibit the dihydroorotate dehydrogenase, thus playing a therapeutic role by transforming into its active metabolite, which is an important key enzyme for the de novo production of pyrimidine by $\mathrm{T}$ lymphocytes and generally has a long plasma lifetime of 14-18 days (7).

In a pilot study conducted by Jakez-Ocampo et al., a total of 16 patients with RA were included, among whom 8 were treated with LFN at a dose of $100 \mathrm{mg} /$ week, and the other 8 cases were treated with conventional dose $20 \mathrm{mg} /$ day for 1 year. The patients' basic treatment did not change, including at least 2 to 3 DMARDs combined with various doses of steroids. The results showed that the initial treatment group with LFN 20 mg/day was beneficial; however, no statistically significant difference between the two groups was observed at the end of this study, although more minor events were observed in patients treated with LFN $20 \mathrm{mg} /$ day (8). In another study, a total of 30 patients with early RA were randomly divided into three groups: the first 10 treated with LFN at a dose of $100 \mathrm{mg} /$ week; the second 10 treated with LFN at a dose of $20 \mathrm{mg} /$ day; and the other 10 treated with MTX at a dose of 7.5-15 mg/week. Again, no significant differences were observed in the variables assessed at the end of the study in any of the 3 groups, and the frequency of adverse events was higher in the LFN $20 \mathrm{mg} /$ day and MTX groups than in the LFN $100 \mathrm{mg} /$ week group (9). Given these findings, we conducted the present study to explore whether a lower dose of LFN is efficacious in the treatment of RA. There was a similar study that compared LFN monotherapy with the combination of 
MTX and LFN (10), but in our study, both LFN and MTX would be compared in a monotherapy setting.

Combining our results with the above findings, we concluded that a lower LFN dose of $10 \mathrm{mg}$ per day could provide a sufficient and sustained response for patients who respond to the drug, allowing better adhesion and compliance than conventional treatment reported in the literature. In addition, there were significantly fewer adverse events reported compared with the recommended standard dose. This scheme also offers the possibility of its use as a monotherapy or in combination with other DMARDs, including MTX, as an attractive option to avoid the use of multiple drugs. In addition, an LFN dose of $10 \mathrm{mg} /$ day could save patients' costs by using lower doses of drugs while maintaining their effectiveness, which is only applicable to countries without a comprehensive wholepopulation health cover system.

\section{Conclusions}

In conclusion, a low dose of LFN at $10 \mathrm{mg} /$ day might be a preferable treatment choice compared with MTX at a dose of $10 \mathrm{mg} /$ week for RA patients. However, this study is a retrospective analysis, which is likely to cause some deviations in the results. It needs to be further confirmed by multi-center clinical trials.

\section{Acknowledgments}

Funding: This study was supported by the Natural Science Foundation of Zhejiang Province (No. LGD21H100003).

\section{Footnote}

Reporting Checklist: The authors have completed the STROBE reporting checklist. Available at https://dx.doi. org/10.21037/apm-21-2331

Data Sharing Statement: Available at https://dx.doi. org/10.21037/apm-21-2331

Conflicts of Interest: All authors have completed the ICMJE uniform disclosure form (available at https://dx.doi. org/10.21037/apm-21-2331). The authors have no conflicts of interest to declare.

Ethical Statement: The authors are accountable for all aspects of the work in ensuring that questions related to the accuracy or integrity of any part of the work are appropriately investigated and resolved. The study was conducted in accordance with the Declaration of Helsinki (as revised in 2013). The study was approved by institutional ethics board of Zhejiang Provincial People's Hospital (No. 2021QT359). Informed consent was not required since this was a retrospective study, and data were obtained from the database of our hospital.

Open Access Statement: This is an Open Access article distributed in accordance with the Creative Commons Attribution-NonCommercial-NoDerivs 4.0 International License (CC BY-NC-ND 4.0), which permits the noncommercial replication and distribution of the article with the strict proviso that no changes or edits are made and the original work is properly cited (including links to both the formal publication through the relevant DOI and the license). See: https://creativecommons.org/licenses/by-nc-nd/4.0/.

\section{References}

1. Scott DL, Smolen JS, Kalden JR, et al. Treatment of active rheumatoid arthritis with leflunomide: two year follow up of a double blind, placebo controlled trial versus sulfasalazine. Ann Rheum Dis 2001;60:913-23.

2. Cohen S, Cannon GW, Schiff M, et al. Two-year, blinded, randomized, controlled trial of treatment of active rheumatoid arthritis with leflunomide compared with methotrexate. Utilization of Leflunomide in the Treatment of Rheumatoid Arthritis Trial Investigator Group. Arthritis Rheum 2001;44:1984-92.

3. Kalden JR, Scott DL, Smolen JS, et al. Improved functional ability in patients with rheumatoid arthritis-longterm treatment with leflunomide versus sulfasalazine. European Leflunomide Study Group. J Rheumatol 2001;28:1983-91.

4. Jaimes-Hernandez J, Robles-San Roman M, SuarezOtero R, et al. Rheumatoid arthritis treatment with weekly leflunomide: an open-label study. J Rheumatol 2004;31:235-7.

5. Arnett FC, Edworthy SM, Bloch DA, et al. The American Rheumatism Association 1987 revised criteria for the classification of rheumatoid arthritis. Arthritis Rheum 1988;31:315-24.

6. Kremer JM. Rheumatological creativity and leflunomide. J Rheumatol 2004;31:203-4.

7. van Roon EN, Jansen TL, van de Laar MA, et al. Therapeutic drug monitoring of A77 1726, the active 
metabolite of leflunomide: serum concentrations predict response to treatment in patients with rheumatoid arthritis. Ann Rheum Dis 2005;64:569-74.

8. Jakez-Ocampo J, Richaud-Patin Y, Simon JA, et al. Weekly dose of leflunomide for the treatment of refractory rheumatoid arthritis: an open pilot comparative study. Joint Bone Spine 2002;69:307-11.

9. Jakez-Ocampo J, Richaud-Patin Y, Granados J, et al.
Weekly leflunomide as monotherapy for recent-onset rheumatoid arthritis. Arthritis Rheum 2004;51:147-8.

10. Guadagnin DA, Mazzali LV, Skare TL, et al. Treating rheumatoid arthritis with leflunomide monotherapy versus combination therapy with methotrexate. Eur J Rheumatol 2021;8:12-5.

(English Language Editor: J. Jones)

Cite this article as: Wang L, Zhang Y, Zhu L, Li Y. Efficacy and safety of methotrexate in the treatment of rheumatoid arthritis: a retrospective study. Ann Palliat Med 2021;10(12):12095-12100. doi: 10.21037/apm-21-2331 